\title{
Dentinogenesis imperfecta type 2
}

\author{
INSERM
}

\section{Source}

INSERM. (1999). Orphanet: an online rare disease and orphan drug data base.

Dentinogenesis imperfecta type 2. ORPHA:166260

Dentinogenesis imperfecta type 2 (DGI-2) is a rare, severe form of dentinogenesis

imperfecta ( $D G l$, see this term) and is characterized by weakness and discoloration of all teeth. 